\title{
BLOOD FLOW AND VASOMOTOR REACTIONS IN THE HAND, FOREARM, FOOT, AND CALF IN RESPONSE TO PHYSICAL AND CHEMICAL STIMULI ${ }^{1}$
}

\author{
By PAUL KUNKEL, EUGENE A. STEAD, JR., AND SOMA WEISS \\ (From the Thorndike Memorial Laboratory, Second and Fourth Medical Services (Harvard), \\ Boston City Hospital, and the Department of Medicine, Harvard Medical School, Boston)
}

(Received for publication November 30, 1938)

In order to obtain an accurate picture of the state of the peripheral circulation it is necessary to know the blood flow and the vasomotor reactions in as many parts of the body as possible. An investigation of the blood flow and the vasomotor reactions of parts of the upper and the lower extremities is of particular significance, not only because of the wide variations in the proportion of muscle to skin in the different parts of the extremities, but also because of the presence in the skin of the hands and feet of numerous arteriovenous anastomoses which have not been demonstrated in other parts of the body (1). In order, therefore, to secure a more complete understanding of the peripheral circulation, the blood flow and the vasomotor reactions in the hand, forearm, foot, and calf at rest were studied by plethysmographic methods. In addition, the changes in the blood flow following exercise and arterial occlusion and the effect of epinephrine and of pitressin on the blood flow were observed in these four parts of the body.

\section{METHOD}

The subjects selected for this study had normal cardiovascular systems. The hand was studied in the plethysmograph described by Freeman (2) and the foot in that described by Stead and Kunkel (3). The plethysmograph of Lewis and Grant (4) was used for the forearm and a similar one of larger size was constructed for the calf. In each case the rubber cuffs closing the instruments were attached to the skin by rubber cement in such a manner as to cause no elevation of the venous pressure; they were prevented from bulging outward by suitable firm, fitted diaphragms. The instruments were connected by pressure tubing to Brodie bellows of $14 \mathrm{cc}$. capacity which recorded the changes in volume on a smoked drum. In order to maintain the water within the forearm and calf plethysmographs at a constant temperature, the instruments were surrounded by large

\footnotetext{
1 The expense of this investigation has been met in part by a grant from the Proctor Fund of Harvard University for the Study of Chronic Disease.
}

water baths; the hand or foot distal to them was exposed to the air. In experiments in which the blood flow and vasomotor reactions of the hand and foot were studied, the water surrounding these organs was constantly circulated by motor driven propellers, but that surrounding the arm and the calf was not mechanically stirred. The water baths were maintained at a constant temperature for at least 30 minutes before blood flow determinations were made. All observations were made with the subjects horizontal and the parts to be tested resting comfortably in the instruments at heart level. In order to measure simultaneously blood flows and vasomotor reactions in various organs, two or three plethysmographs were usually applied, though in no case was more than one instrument applied to the same extremity.

These plethysmographs could be used for the determination of the blood flow to the enclosed portion of the extremity, since the initial rate of increase in volume produced by applying a collecting pressure just proximal to the instrument was a measure of the blood flow. The method used for calibrating the instruments and for calculating the blood flow was the same as that previously described for the determination of blood flow in the foot (3). As two rubber diaphragms had to be stabilized in the forearm and calf plethysmographs, these instruments were'found to be less accurate than the hand and foot plethysmographs. Unless otherwise stated, the blood flows are recorded as cubic centimeters of blood per minute per $100 \mathrm{cc}$. of tissue.

In some instances the surface area of the part enclosed within the plethysmograph was measured by making a light plaster mold of the part. This mold was cut while still soft and made to lie flat by multiple incisions; its outline was traced on cardboard, which was then weighed. The surface area of the mold was calculated from the known weight of $100 \mathrm{sq}$. $\mathrm{cm}$. of the cardboard.

\section{Influence of circulation in the hand and foot on measurements of blood flow in the forearm and calf}

Recently Grant and Pearson (5) have shown that the plethysmographic method of measuring the blood flow to the forearm was not accurate under all conditions unless the circulation to the hand was completely obstructed by a cuff just distal to the forearm plethysmograph. Our observations agreed with this. If the blood flow in the 
hand was rapid in comparison with the flow in the forearm, when the collecting pressure was applied the rate of increase in the volume of the forearm was greater than that caused by the arterial inflow to the tissues of the forearm. This was due to the trapping in the veins of the forearm of the blood returning from the hand. With the body cool and the forearm bath at $30^{\circ} \mathrm{C}$., the blood returned from the hand slowly enough not to influence appreciably the measurement of the blood flow in the forearm. When the body was heated, however, the flow to the hand increased much more than that to the forearm and, if the circulation to the hand was not obstructed, the calculated values for the flow in the forearm were greater than the true values. When the water bath surrounding the forearm was maintained at $43^{\circ} \mathrm{C}$. the circulation in the forearm was so rapid that the venous return from the hand had little effect on the measurement of the forearm flow, regardless of whether or not the body was heated. In 5 experiments on 3 subjects at room temperatures from 20 to $28^{\circ} \mathrm{C}$. and with the forearm bath at $43^{\circ} \mathrm{C}$., the forearm flows averaged $10.4,14.9$ and $8.8 \mathrm{cc}$. per minute, respectively; after the circulation to the hand was occluded by inflating a cuff distal to the plethysmograph to $300 \mathrm{~mm}$. $\mathrm{Hg}$ the flows averaged 9.5, 14.7 , and $8.7 \mathrm{cc}$., respectively. During the reactive hyperemia following arterial occlusion Grant and Pearson (5) found the forearm flow to be so rapid that the returning blood from the hand had no effect on it.

In the studies of the vasomotor reactions of the forearm and calf reported here, the circulation to the hand and the foot was always completely obstructed by suddenly inflating cuffs just distal to the plethysmographs to $300 \mathrm{~mm}$. Hg. From 30 seconds to 2 minutes were allowed for the base line to become level before readings were taken. Occluding cuffs were also used in studying the effects of epinephrine and pitressin when the temperature of the forearm bath was below $43^{\circ}$ C., and in some instances when the water bath was at $43^{\circ} \mathrm{C}$. They were usually applied when the blood flow was determined with the water bath at 32 to $37^{\circ} \mathrm{C}$.; when the temperature of the room was not high enough to cause vasodilatation in the hand or the foot they were not used. In the study of the effects of exercise and of ar- terial occlusion in the forearm and calf the circulation of the hands and feet was always undisturbed.

\section{OBSERVATIONS}

\section{$V$ asomotor reactions in the forearm and calf}

The vasomotor responses in the forearm and the calf of 9 normal subjects were studied with the water bath at temperatures of from 8 to $43^{\circ}$ C. The circulation distal to the plethysmographs was obliterated by inflating cuffs to a pressure of $300 \mathrm{~mm}$. Hg. In the 2 subjects who showed the greatest responses, repeated observations were made on different days and the temperature of both the room and the water bath was varied. The stimuli routinely used to elicit vasomotor responses were pinching the skin of the chest, noise, and a deep inspiration. In a few instances mental arithmetic and the sudden application of an ice cold towel to the chest were employed. The pinches always produced pain; the noises were unexpected and loud, in order to startle the subject if possible. Less intense stimuli usually gave little or no response. The forearm and calf responded to these stimuli in one of three ways : (1) with a decrease in volume; (2) with an increase in volume; or (3) with a biphasic reaction, i.e., an increase followed by a decrease in volume.

Decrease in volume. Six of the 9 subjects exhibited a decrease in volume of the forearm following noise or pinch; 3 showed no change. Four showed a decrease in volume of the calf after noise or pinch; 5 showed no change (Figure $1-B)$. Five subjects showed a decrease in volume of both the calf and the forearm after a deep inspiration (Figure $1-A$ ), and 3 showed no change. One was not tested. Two subjects showed no response to any stimulus in either the forearm or the calf. For reasons to be stated below, the decreases in volume of the parts are considered to be the result of active vasoconstriction and will be called constrictor responses.

The constrictor responses in the forearm and the calf paralleled the vasoconstrictor reactions which have been shown to occur in the hand and the foot following similar sensory stimuli. They had a similar latent period of from 3 to 9 seconds and likewise were abolished when complete vasoconstriction was caused by cold, and greatly diminished in intensity or abolished when the vessels 


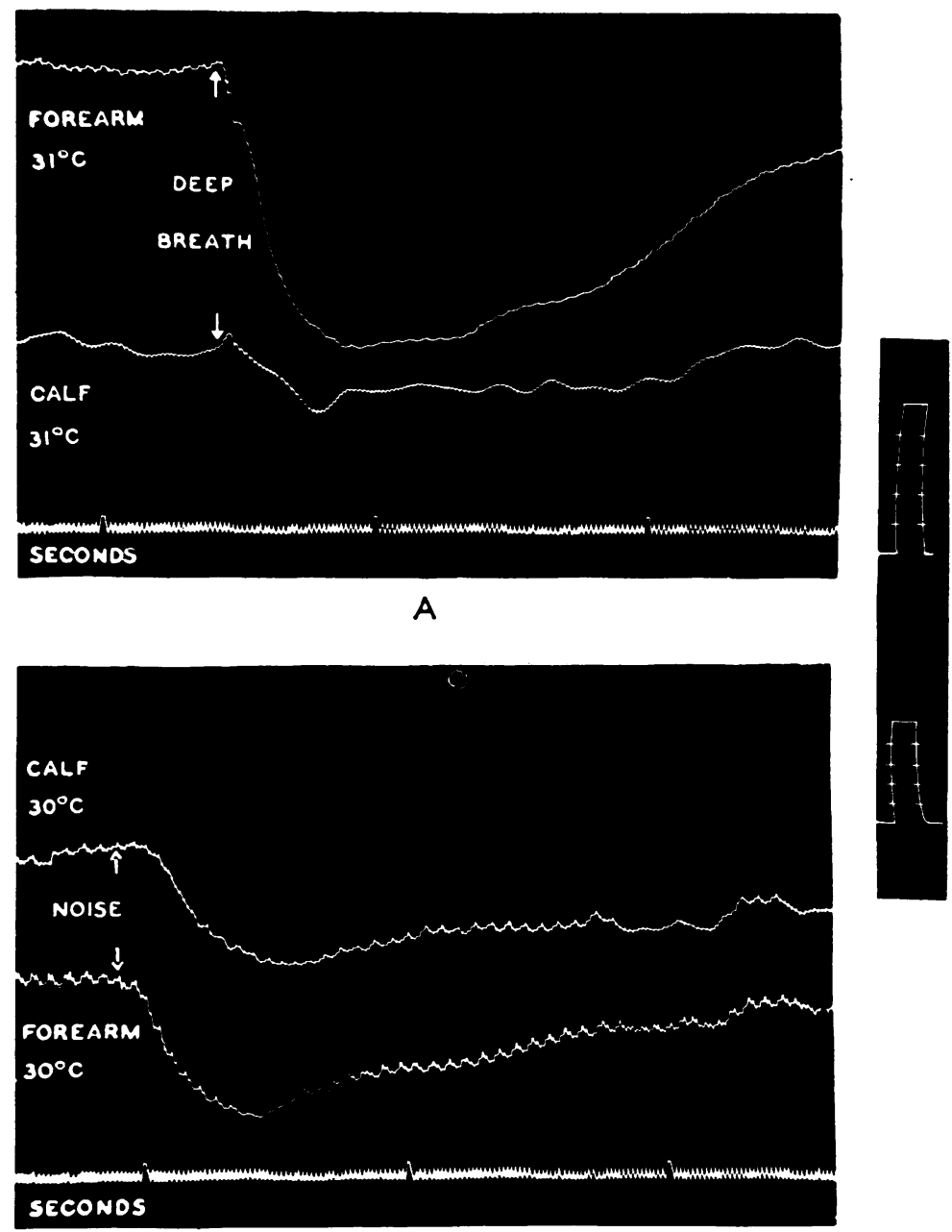

B

Fig. 1. Vasoconstriction in the Forearm and Calf

In this and the following figures a rise in the base line indicates an increase, while a fall indicates a decrease in volume. The calibrations are in cubic centimeters ; upper $=$ forearm, lower $=$ calf.

$A$. The effect of a deep breath. Room temperature $26^{\circ} \mathrm{C}$.

$B$. The effect of a sudden noise. Room temperature $32^{\circ} \mathrm{C}$.

were sufficiently dilated by local heat. They usually lasted from 1 to 3 minutes, but at times were of even longer duration. The intensity of the stimuli necessary to produce vasomotor responses in the forearm and the calf was greater than that required for the hand and the foot, and the magnitude of the response as measured in cubic centimeters per $100 \mathrm{cc}$. of tissue was usually less than in the hand and the foot.

As in the hand and the foot, there was great variation in the degree of vasomotor response, not only in different subjects but also in the same subject on different days. The temperature range over which good constrictor responses were obtained in the forearm and the calf was, however, not so great as in the hand and the foot. The ideal temperature for obtaining the constrictor responses varied from subject to subject. In any one person both the environmental temperature and the temperature of the water bath influenced the state of the vessels. In general, the responses were greatest with the room temperature between 30 and $33^{\circ} \mathrm{C}$. and the temperature of the water bath between 30 and $37^{\circ} \mathrm{C}$. Under these condi- 
tions the subjects usually exhibited generalized vasodilatation. With the water bath at $43^{\circ} \mathrm{C}$. or above, or at $20^{\circ} \mathrm{C}$. or below, vasoconstrictor impulses were rarely obtained in response to noise or pinch, though at times a deep breath was still effective. As a rule the vasoconstrictor responses in the forearm were greater, more easily obtained, and persisted over a greater range of temperature than those in the calf. Cold was as effective a stimulus as noise or pinch; mental arithmetic produced less response.

It is well known that the efferent pathway for vasoconstrictor responses to sensory stimuli in the hand and the foot is through the sympathetic nerves supplying the vessels. As the vasoconstrictor responses in the forearm and the calf are similar to those in the hand and the foot, it is assumed that they also are transmitted by the sympathetic nerves. Since they are produced by such stimuli as noise and pinch, which do not cause a fall in blood pressure, the decrease in volume must be the result of active vasoconstriction in the ressels of the part inclosed within the plethysmograph.

Increase in volume. In adclition to the constrictor responses, 4 of the 9 subjects showed at
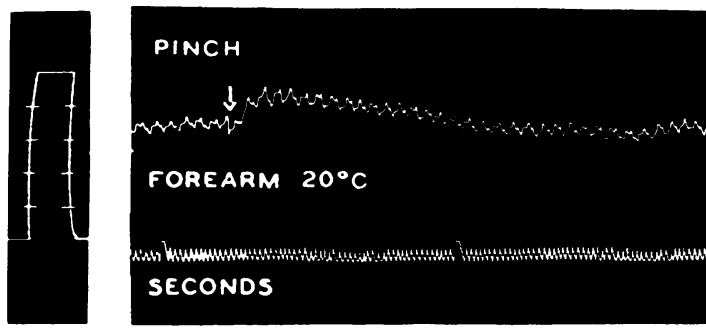

\section{A}
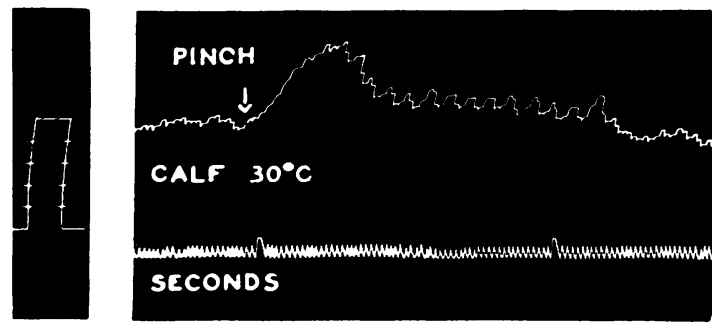

B some time during the experiments an increase in the volume of the forearm and calf following noise, pinch, or the application of ice cold towels (Figure $2-A$ and $B$ ). For convenience, any increase in volume, regardless of the mechanism by which it is produced, will be called a dilator response. These responses were obtained less frequently than the constrictor responses. They were obtained at times with the water bath at temperatures from 10 to $43^{\circ} \mathrm{C}$. They were never produced by mild stimuli, but occurred only when the patient had actual pain, was frightened by the noise, or experienced actual discomfort from the ice cold towel. The stimuli employed were usually intense enough to produce quickening and deepening of the respiration and an increase in the force of the apex impulse. They frequently caused a rise in the blood pressure, but at times when an increase in volume was measured no increase in the blood pressure could be detected by the auscultatory method. The latent period between the application of the stimulus and the beginning of the increase in volume usually dicl not exceed 2 seconds and frequently was too short to measure by our apparatus. The duration of the dilator responses was usually from 15 to 30

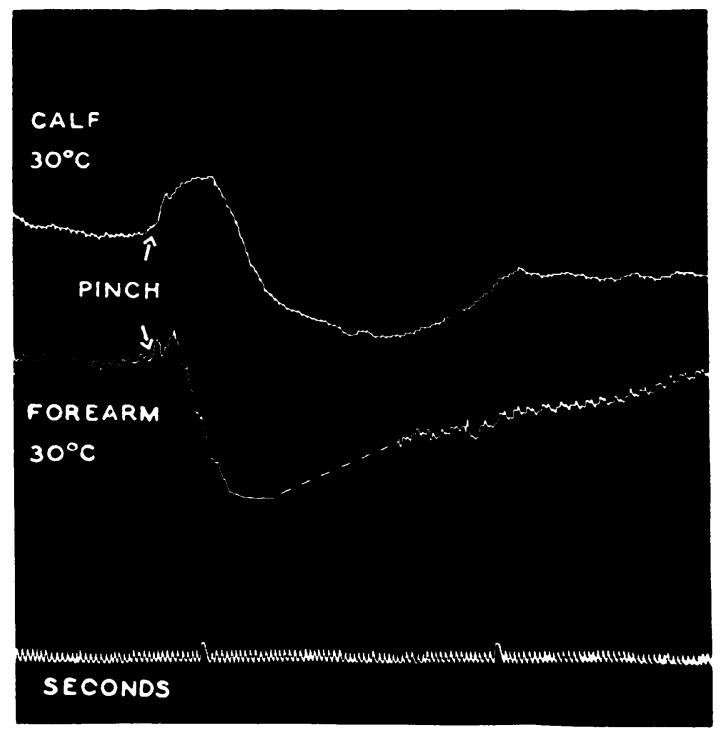

C

Fig. 2. Dilator and Biphasic Responses in the Forearm and Calf

$A$ and $B$. Dilatation incluced by pinching the skin. Room temperature: $A, 32^{\circ} \mathrm{C}$; $B, 27^{\circ} \mathrm{C}$.

$C$. Dilatation followed by constriction in the calf produced by pinching the skin; vasoconstriction in the forearm from the same stimulus. Room temperature $32^{\circ} \mathrm{C}$. 
seconds, in contrast to the constrictor response, which typically lasted from 1 to 3 minutes. Unlike the constrictor responses, dilatation was more easily obtained early in the experiment, especially in the cases in which noise was the most effective stimulus. As the subjects became accustomed to the noise, its effect on the circulation diminished. Blood flow determinations made at the height of the dilator responses in the subject who showed the greatest increases in volume in the forearm and the calf showed no measurable change in the blood flow.

Biphasic reaction. The third type of response was characterized by an increase in volume, followed by a decrease (Figure 2-C). These biphasic responses were usually greatest with the water bath at or near $30^{\circ} \mathrm{C}$. As in the monophasic reactions, the latent period preceding the increase in volume was short.

The dilator responses observed following sensory stimulation can be explained in four ways. They may be due to $(a)$ active reflex vasodilatation; (b) a passive increase in the volume of the part as a result of vasoconstriction in the portion of the extremity proximal to the plethysmograph; (c) a passive increase in the volume of blood in the veins as a result of an increase in intrathoracic pressure; $(d)$ a slight increase in the volume of the vascular bed owing to a transient increase in cardiac output.

(a) When the increases in volume in the forearm and the calf were first observed it was assumed that they were the result of changes occurring in the muscles, since we had not observed similar responses in the hand and the foot, which contain little muscle as compared with the forearm and the calf. In view of the fact that the stimuli used in the previous investigation had been weaker, however, the vasomotor responses in the hand and the foot were retested in the 2 subjects giving the greatest increase in volume in the forearm and the calf. The stimuli were of the same character and intensity as those used in the observations on the forearm and the calf. One subject showed on two different days an increase in volume followed by slight constriction in both the hand and the foot (Figure 3 ). In this case the water bath was cold enough nearly to obliterate

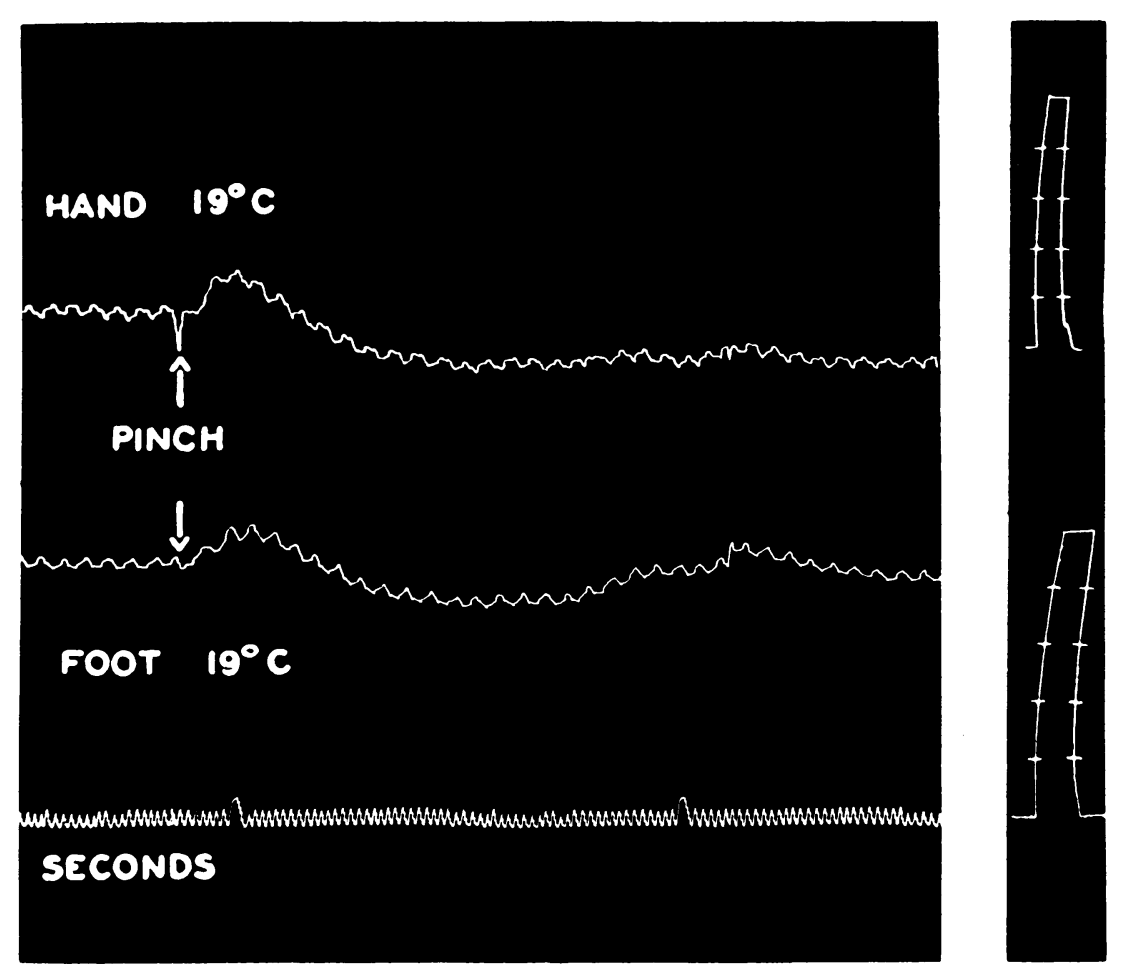

Fig. 3. Dilatation Followed by Slight Constriction in the Hand and Foot. RoOM TeMperature $23^{\circ} \mathrm{C}$. 
the constrictor response. The second subject showed the biphasic response only in the foot. Again, the latent periods preceding the increases in volume were short. This demonstration of an increase in volume in the hand and the foot, which contain little muscle, indicates that the similar response in the forearm and the calf is probably not the result of active vasodilatation occurring in the muscles of the forearm and the calf. Moreover, it is unlikely that the increase in volume is the result of active vasodilatation occurring in the skin, since the response in the forearm and the calf is obtained at times when the skin vessels are already greatly dilated by a local temperature of $43^{\circ} \mathrm{C}$.

(b) It is possible that the increase in volume is the result of vasoconstriction in the portion of the extremity proximal to the plethysmograph. Regardless of whether the vessels inclosed in the plethysmograph are constricted by local cold or dilated by local heat, the vessels proximal to the plethysmograph may still be able to constrict. If the vessels inclosed within the plethysmograph did not change in caliber because they were either dilated by local heat or constricted by local cold, the effective blood pressure in these vessels might be raised as a result of vasoconstriction in other parts of the extremity. The short latent period preceding the increases in volume and the brief duration of the dilator responses as compared with the constrictor responses are against this explanation.

(c) Changes in intrathoracic pressure influence the volume of the parts inclosed in the plethysmographs, and produce the small respiratory waves frequently noted in the tracings (6). A slight expiratory effort against a closed glottis will produce an increase in intrathoracic pressure, which will cause the venous pressure to rise and increase the volume of the forearm and the calf. A few quick breaths also will at times produce an increase in the calf volume. Tracings of the increases in volume thus produced differ in two respects from tracings of increases resulting from stimuli such as pinch or noise: (1) When the breathing returns to normal the volume immediately returns to the base line; (2) the individual respiratory waves are larger.

(d) The dilator response to sensory stimuli is best explained as the result of a slight increase in the volume of the vascular bed owing to a transient increase in cardiac output. This increase in cardiac output would not have to be great, as the maximum increase in volume was about $4 \mathrm{cc}$. in a calf having a volume of $1800 \mathrm{cc}$., or about $0.22 \mathrm{cc}$. per $100 \mathrm{cc}$. of calf. It is true that by the auscultatory method the blood pressure did not always rise. It is possible, however, that the increase in pressure necessary to produce in an elastic system the volume changes observed may be very small. While no measurements of cardiac output have been made in the first few seconds following sensory stimulation, an increase may well occur, as it has been shown that the latent period preceding the increase in pulse rate is short. The latent period preceding acceleration of the heart rate at the beginning of voluntary exercise is one cardiac cycle or less (7). Bainbridge (8), using anesthetized dogs, found that following stimulation of the central end of the sciatic nerve the heart rate increased after a latent period usually not exceeding 1 to 2 seconds. These authors $(7,8)$ showed that this initial acceleration of the heart rate was the result of a decrease in vagal tone and not the result of stimulation of the cardiac accelerator nerves. In 1 subject observed by us the effect of noise and pinch on the heart rate was studied with the electrocardiograph. After pinch the heart rate became more rapid for 3 to 4 beats; after noise the heart rate showed little change. This subject gave much better dilator responses to pinch than to noise.

If the increase in volume of the part resulted from increased cardiac output, the amount of increase would be influenced by both the size of the part and the degree of dilatation of the arterial bed before the stimulus is given. The greater amount of tissue present in the calf accounts for the ease with which dilator responses are obtained in the calf as compared with the forearm. The influence of the amount of dilatation of the vascular bed cannot be interpreted with such ease, as in 1 subject as large increases in volume were obtained at $10^{\circ}$ as at $43^{\circ} \mathrm{C}$.

\section{Effect of local heat, arterial occlusion, and exercise on blood flow in the hand, forearm, foot, and calf in normal subjects}

Local heat. In subjects lying quietly in a comfortable position in a room at a temperature of 
from 20 to $28^{\circ} \mathrm{C}$. and with the water bath at $32^{\circ} \mathrm{C}$., the values for the blood flow to the forearm and foot in 4 subjects and to the calf in 5 subjects each were at about the same level, i.e., less than $3 \mathrm{cc}$. per minute per $100 \mathrm{cc}$. of tissue. The blood flow to the hand was somewhat greater, averaging $5 \mathrm{cc}$. in 8 persons. When the temperature of the water bath was raised the flow increased in all parts. At a room temperature of from 22 to $26^{\circ} \mathrm{C}$. with the water bath at $37^{\circ} \mathrm{C}$. the average values were: hand ( 6 subjects) 10 cc.; forearm (4 subjects), foot (4 subjects), and calf ( 2 subjects) around $5 \mathrm{cc}$. With the water bath at $43^{\circ} \mathrm{C}$. the average flows increased to: hand (18 subjects) $32 \mathrm{cc}$; foot (34 subjects) 17 cc. ; forearm ( 7 subjects) $14 \mathrm{cc}$; and calf (9 subjects) $9.5 \mathrm{cc}$. The blood flow at $43^{\circ} \mathrm{C}$. was little affected by variations in room temperature between 20 and $30^{\circ} \mathrm{C}$. Table I gives the figures for the blood flow at $43^{\circ} \mathrm{C}$. in the hand, foot, forearm, and calf in 4 subjects.

TABLE I

Blood flow in the hand, forearm, foot, and calf at $43^{\circ} \mathrm{C}$. recorded as cubic centimeters per minute per $100 \mathrm{cc}$. of tissue

\begin{tabular}{|c|c|c|c|c|c|c|c|c|}
\hline \multirow{2}{*}{ Subject } & \multicolumn{2}{|c|}{ Hand } & \multicolumn{2}{|c|}{ Forearm } & \multicolumn{2}{|c|}{ Foot } & \multicolumn{2}{|c|}{ Calf } \\
\hline & $\begin{array}{l}\text { Blood } \\
\text { flow }\end{array}$ & $\begin{array}{l}\text { Vol- } \\
\text { ume }\end{array}$ & $\begin{array}{l}\text { Blood } \\
\text { flow }\end{array}$ & $\begin{array}{l}\text { Vol- } \\
\text { ume }\end{array}$ & $\begin{array}{l}\text { Blood } \\
\text { flow }\end{array}$ & $\begin{array}{l}\text { Vol- } \\
\text { ume }\end{array}$ & $\begin{array}{l}\text { Blood } \\
\text { flow }\end{array}$ & $\begin{array}{l}\text { Vol- } \\
\text { ume }\end{array}$ \\
\hline $\begin{array}{l}\text { E. S. . } \\
\text { P. K... } \\
\text { H. F... } \\
\text { E. A... }\end{array}$ & $\begin{array}{l}47 \\
29 \\
28 \\
54\end{array}$ & $\begin{array}{c}c c . \\
462 \\
534 \\
370 \\
580\end{array}$ & $\begin{array}{l}11 \\
11 \\
16 \\
16\end{array}$ & $\begin{array}{l}c c . \\
748 \\
870 \\
673 \\
680\end{array}$ & $\begin{array}{l}16 \\
16 \\
18 \\
15\end{array}$ & $\begin{array}{r}c c . \\
1175 \\
1266 \\
888 \\
1260\end{array}$ & $\begin{array}{c}5 \\
5 \\
16 \\
10.9\end{array}$ & $\begin{array}{c}c c . \\
1965 \\
1920 \\
1430 \\
1280\end{array}$ \\
\hline
\end{tabular}

With the water bath at 32 to $37^{\circ} \mathrm{C}$. the blood flow in the hand and the foot was greatly' increased by heating the body. No studies were made of the effect on the forearm and calf flows produced by heating the body. Grant and Pearson (5), however, have shown that on moderate heating of the body there is little increase in the forearm and calf flows as compared with the increase in flow in the hand and foot. Recently Grant and Holling (9) have reported a considerable increase in forearm flow following intense heating of the body. We found that raising the local temperatures produced a definite progressive rise in the blood flow in the forearm and the calf.

The presence of arteriovenous anastomoses in the skin of the hand and foot (1) suggested that the blood flow in the skin of the hand and the foot might be greater than that in the skin of the forearm and the calf. For the purpose of comparison, the surface area of the respective parts was determined and the blood flow at $43^{\circ} \mathrm{C}$. calculated as cubic centimeters per minute per 100 sq. cm. of skin (Table II). Thus the mass of

TABLE II

Blood flow in the hand, forearm, foot, and calf at $43^{\circ} \mathrm{C}$. recorded as cubic centimeters per minute per 100 sq. cm. of surface area

\begin{tabular}{|c|c|c|c|c|c|c|c|c|}
\hline \multirow{2}{*}{ Subject } & \multicolumn{2}{|c|}{ Hand } & \multicolumn{2}{|c|}{ Forearm } & \multicolumn{2}{|c|}{ Foot } & \multicolumn{2}{|c|}{ Calf } \\
\hline & $\begin{array}{l}\text { Blood } \\
\text { flow }\end{array}$ & $\begin{array}{l}\text { Skin } \\
\text { area }\end{array}$ & $\begin{array}{l}\text { Blood } \\
\text { flow }\end{array}$ & $\begin{array}{l}\text { Skin } \\
\text { area }\end{array}$ & $\begin{array}{l}\text { Blood } \\
\text { flow }\end{array}$ & $\begin{array}{l}\text { Skin } \\
\text { area }\end{array}$ & $\begin{array}{l}\text { Blood } \\
\text { flow }\end{array}$ & $\begin{array}{l}\text { Skin } \\
\text { area }\end{array}$ \\
\hline $\begin{array}{l}\text { E. S. . . } \\
\text { P. K.... }\end{array}$ & $\begin{array}{l}45 \\
28\end{array}$ & $\begin{array}{c}\text { sq. cm. } \\
482 \\
548\end{array}$ & $\begin{array}{l}23 \\
22\end{array}$ & $\begin{array}{c}s q . \mathrm{cm} \\
393 \\
450\end{array}$ & $\begin{array}{l}28 \\
26\end{array}$ & $\begin{array}{c}\text { sq. cm. } \\
678 \\
781\end{array}$ & $\begin{array}{l}15 \\
17\end{array}$ & $\begin{array}{c}\text { sq. } \mathrm{cm} . \\
656 \\
653\end{array}$ \\
\hline
\end{tabular}

muscle present in the calf and the forearm was completely disregarded and the parts were treated as if the entire blood flow were to the skin. The flow in the hand calculated in this way was still greater than the flow in the other parts examined. The flow in the foot was also greater than that in the forearm and the calf.

Arterial occlusion. In order to determine to what extent the local heat of $43^{\circ} \mathrm{C}$. produced vasodilatation in the various parts, the heat stimulus was reinforced in the hand, forearm, and foot in 2 subjects by a 5 -minute period of arterial occlusion obtained by suddenly inflating cuffs proximal to the plethysmographs to a pressure of 300 $\mathrm{mm}$. Hg. Blood flow determinations were made before and after the occlusion. In the foot, the vessels were so completely dilated that in the period immediately following the arterial occlusion very little change in blood flow occurred. In the hand the flow increased between 25 and 50 per cent, but that in the forearm increased as much as 500 per cent. The difference between the response of the hand and foot may be due to the fact that the hand contains proportionally more muscle. However, the observed difference may be accounted for by the fact that the hydrostatic pressure is considerably greater in the foot than in the hand plethysmograph.

Exercise. Studies were made of the effect of exercise on the blood flow in the muscles of the forearm in 2 subjects and in the calf in 5 subjects. The exercise in the forearm consisted in 
tightly closing and opening the fist at the rate of about 90 times per minute for 3 minutes, the muscles of the forearm being held as taut as possible. The exercise in the calf consisted of 3-minute periods of flexing and extending the ankle at the rate of about 60 times per minute. Flows were taken immediately after the period of exercise. The exercise in the forearm produced no constant change in the flow of the hand at temperatures of the water bath varying from 32 to $43^{\circ} \mathrm{C}$., as it involved few of the muscles of the hand. However, it invariably produced a marked increase in the blood flow in the forearm. The actual increase in flow in the forearm was approximately the same (16 to $20 \mathrm{cc}$. per $100 \mathrm{cc}$. of tissue) regardless of whether the resting flow was $2 \mathrm{cc}$. at $32^{\circ} \mathrm{C}$. or $10 \mathrm{cc}$. at $43^{\circ} \mathrm{C}$. In the calf the increases in blood flow after exercise were rarely as striking. In 5 subjects at $43^{\circ} \mathrm{C}$. the increase averaged $7 \mathrm{cc}$. per minute per $100 \mathrm{cc}$. In 1 subject tested at both temperatures the increase was the same at 32 and $43^{\circ} \mathrm{C}$. The subjects were not able to keep the calf muscles taut during the period of exercise and this probably allowed better circulation through these muscles during exercise than occurred in the muscles of the forearm. The effect of 3-minute exercise of the toes was tried out in 1 subject at $30^{\circ} \mathrm{C}$., and a rise in blood flow in the foot of only $1 \mathrm{cc}$. was obtained.

In organs which contain comparatively little muscle, such as the hand and the foot, external heat produces relatively complete dilatation and little further increase in blood flow can be induced by a 5 -minute period of arterial occlusion. In the forearm, however, external heat causes great dilatation only in the vessels of the skin. Therefore, when the vessels of the muscle are dilated by arterial occlusion, the blood flow is greatly increased. Likewise, the fact that a given amount of exercise in the forearm and the calf produces approximately the same degree of increase in blood flow above the resting level at temperatures of from 32 to $43^{\circ} \mathrm{C}$. is evidence that the major portion of the vasodilatation resulting from the heat occurs in the skin.

\section{Effect of epinephrine and pitressin on blood flow in the hand, forearm, foot, and calf}

Epinephrine. Epinephrine hydrochloride, $1 \mathrm{cc}$. of a $1 / 1000$ solution, was injected subcutaneously.
In the amounts used, epinephrine always caused a well marked increase in the pulse rate, systolic pressure and pulse pressure, and a fall in the diastolic pressure. The subjects became pale and complained of palpitation. At $43^{\circ}$ C. marked vasoconstriction occurred in the hand and foot, usually lasting for 2 hours. In 4 subjects the average flow in the hand fell from 38 to $15 \mathrm{cc}$. per minute per $100 \mathrm{cc}$. of tissue following the administration of epinephrine; the average flow in the foot in 2 subjects fell from 14 to 6 cc.

In the forearm and the calf the flow never decreased; usually it showed a definite increase coincident with the marked increase in the amplitude of the pulse waves (Figure 4). A slight increase in flow persisted after the pulse rate and the blood pressure had returned to the resting level. The greatest increase in blood flow usually occurred at the height of the rise in pulse rate and systolic blood pressure. In 8 experiments on 5 subjects at $43^{\circ} \mathrm{C}$. the average maximal increase in forearm flow was 4 cc., an increase of 40 per cent. As the average forearm volume was 751 cc., this was an increase of $30 \mathrm{cc}$. per minute in the flow to the mass of forearm inclosed. In 1 subject at $31^{\circ} \mathrm{C}$. the forearm flow increased from 2 to 7 cc., an increase in total flow of $43 \mathrm{cc}$. per minute. In another subject at $20^{\circ} \mathrm{C}$. the flow increased from 1.5 to 3 cc., or an increase in total flow of $13 \mathrm{cc}$. per minute.

The calf was studied in only 2 subjects at $43^{\circ}$ $C_{\text {. }}$; in one the flow showed no change and in the other the flow increased from 9 to $11 \mathrm{cc}$. As the calf volume was $1400 \mathrm{cc}$. this represented a rise of $28 \mathrm{cc}$. per minute in the blood flow to the part of the calf inclosed in the plethysmograph. In 2 subjects at $31^{\circ} \mathrm{C}$. the average calf flow increased from 1 to $3.5 \mathrm{cc}$. This represented an increase of $50 \mathrm{cc}$. per minute to the portion of the calf within the plethysmograph (Figure 5).

Blood flow determinations were made before and after exercise of the forearm muscles in order to ascertain whether epinephrine altered the ability of these vessels to dilate. Three-minute periods of exercise were carried out in the forearm as previously described with the water bath at $43^{\circ}$ C. Epinephrine, $1 \mathrm{cc}$. of $1 / 1000$ solution, was then injected subcutaneously and similar periods of exercise performed while the vasoconstriction in the hand and the foot was maximal. The ves- 


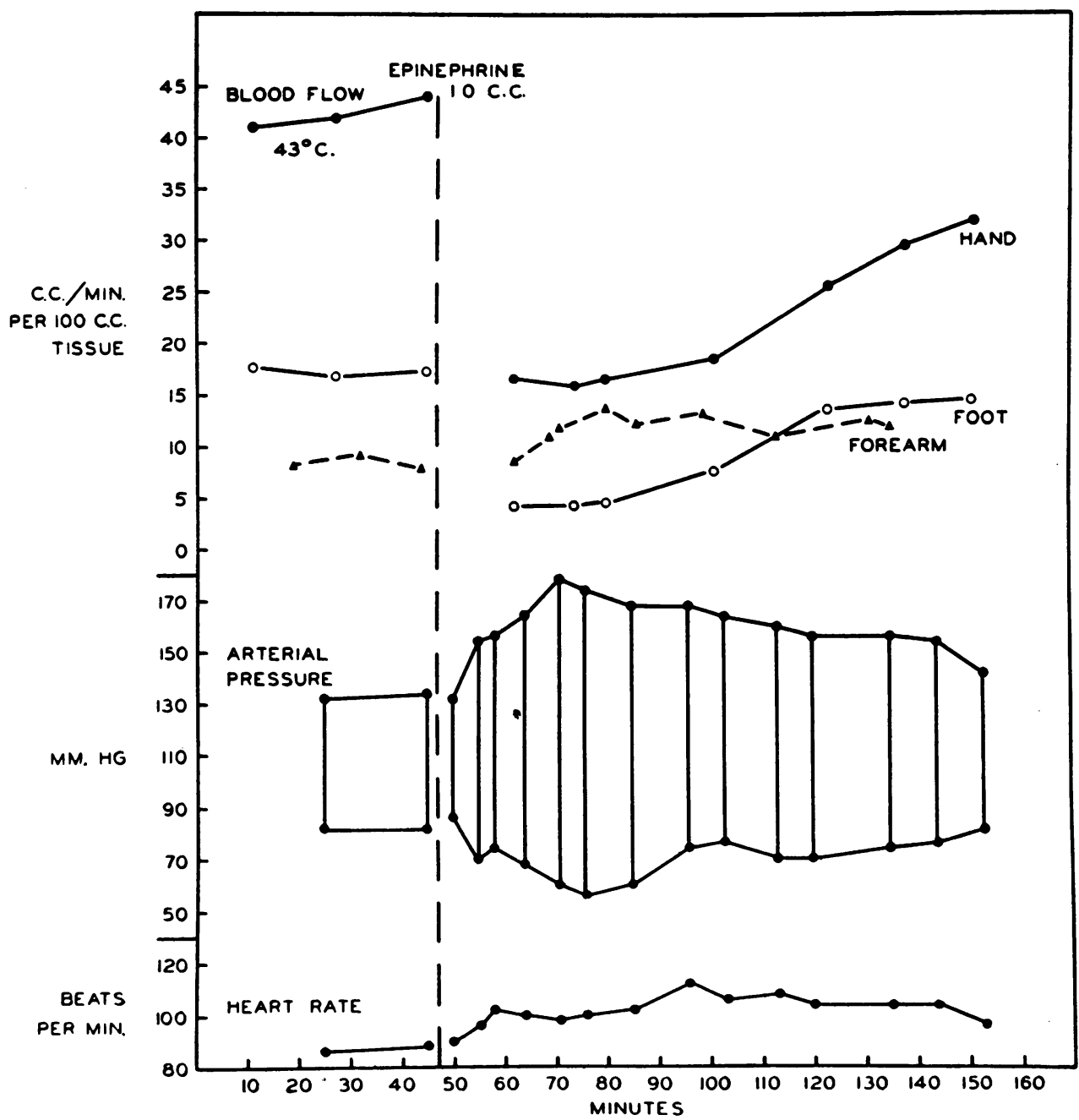

Fig. 4. Effect of Epinephrine, 1 cc. of $1 / 1000$ Solution Subcutaneously, on Blood Flow in the Hand, Forearm, and Foot in the Same Subject at $43^{\circ} \mathrm{C}$.

Determinations in the hand and foot were made simultaneously; measurements in the forearm were taken on another day.

sels dilated as fully with exercise as they did before injection of epinephrine. Since the exercise was difficult to quantitate, the blood flow was determined in the forearm at $43^{\circ} \mathrm{C}$. in the period of reactive hyperemia following 3-minute arterial occlusion before and after the subcutaneous injection of $1 \mathrm{cc}$. of $1 / 1000$ solution of epinephrine. The resting flow of the forearm was increased by the epinephrine; the response to arterial occlusion was not altered.

Pitressin. Observations were made on the effects of $1 \mathrm{cc}$. of pitressin injected intramuscularly on the blood flow, the blood pressure, and the pulse rate. Pitressin produced very little change in the pulse rate or the blood pressure, the characteristic effect being no change in the systolic and a slight elevation of the diastolic blood pressure. All the subjects became pale and usually complained of abdominal cramps. In 6 experiments on 4 subjects with the water bath at $43^{\circ} \mathrm{C}$. injection of pitressin produced a decrease in the average blood flow in the hand from 43 to $15 \mathrm{cc}$; in 2 subjects the average foot flow dropped from 16 to $6 \mathrm{cc}$. In 6 experiments on 4 subjects the average flow in the forearm decreased from 13 to $10 \mathrm{cc}$. at the height of the pitressin effect; in 1 case, however, 


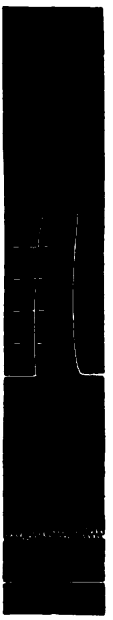

A

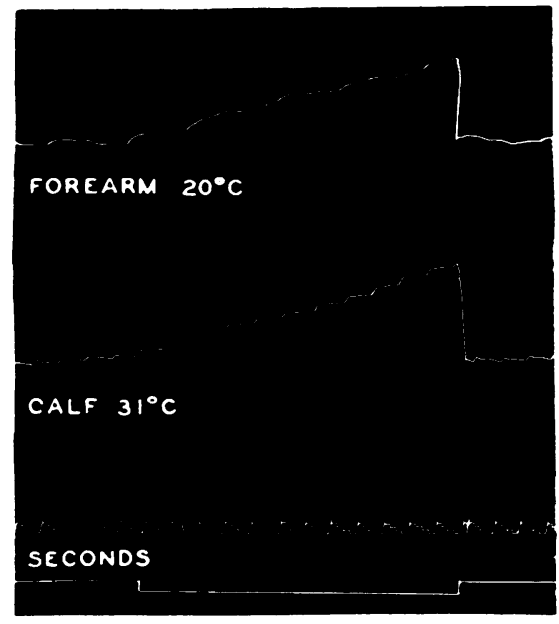

B

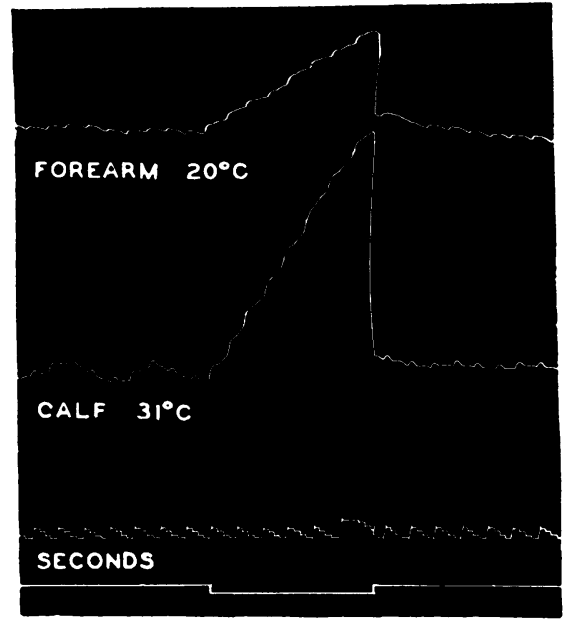

C

Fig. 5. Simpltaneols Tricings Showing Effect of Epinephrine, 1 ce. of 1/1000 Solution Subcutaneously, on Bloon Flow in the Forearm at $20^{\circ}$ C. and in the Calf at $31^{\circ}$ C.

A. Calibration in cubic centimeters; upper $=$ forearm, lower $=$ calf.

B. Flow tracings before epinephrine.

C. Flow tracings after epinephrine. Forearm volume $=850 \mathrm{cc}$, calf $2025 \mathrm{cc}$.

no change occurred. In the calf in 1 subject at $43^{\circ} \mathrm{C}$. the flow decreased from 11 to $5 \mathrm{cc}$. Studies were made at $43^{\circ} \mathrm{C}$. on the response of the vessels of the forearm muscles to 3 -minute periods of exercise, before and after injection of pitressin. After pitressin the resting forearm flow fell slightly, but after exercise it increased above the base line the same as before pitressin. In spite of the drop in the forearm flow the vessels of the muscles were able to dilate normally.

\section{DISCUSSION}

From these observations, the vasomotor reactions in the forearm and the calf appear to be qualitatively identical with those present in the hand and the foot. The constrictor response described is mainly or entirely the result of changes in the vessels of the skin of the forearm and the calf. The sensitivity of individuals to vasomotor stimuli varies considerably. We have observed persons in whom powerful vasoconstriction developed even in the presence of vasodilatation induced by local heat of $43^{\circ} \mathrm{C}$. Grant and Pearson (5) state that they obtained either an increase or no change in volume in the forearm and the calf following sensory stimulation and that in no instance did they elicit vasoconstrictor responses.
In their illustration of increase in volume following a sudden noise the room temperature was $13^{\circ}$ and the temperature of the water bath $30^{\circ} \mathrm{C}$. Since our best constrictor responses were obtained in a warm room, the difference in room temperature may account for their failure to obtain constrictor responses. While our data suggest that the dilator responses are not the result of active vasodilatation, the responses in the sympathectomized forearm and calf must be studied before final conclusions can be drawn. Such a study will require several subjects since under the conditions of our experiments several normal persons give no dilator responses.

In the majority of the subjects the vasomotor responses were more easily obtained in the forearm than in the calf. When vasoconstriction was produced in both organs the change in volume was usually greater in the forearm than in the calf. Likewise, as shown by the greater blood flow at $43^{\circ} \mathrm{C}$., the vessels of the forearm were able to dilate more widely than those of the calf, and the vessels of the hand more widlely than those of the foot. This observation that the response of the vessels of the forearm to various stimuli is greater than the response in the calf is in accord with the observations of other ob- 
servers that the blood vessels of the upper part of the body are more sensitive to both chemical and nervous stimuli than those of the lower extremities. It has been shown that the flushing of the skin produced by chemical agents, such as histamine (10) and acetylcholine (11), is greater in the upper part of the body. Likewise, Ellis and Weiss (12) in a study of the vasomotor reactions in subjects with hemiplegia demonstrated that the disturbances of the vasomotor system pro- duced by the lesions in the central nervous system were much more marked in the upper than in the lower extremity. They showed that edema occurred frequently in the paralyzed upper extremity, but only rarely in the paralyzed lower extremity and that it was the result of decreased peripheral resistance due to arteriolar dilatation. This arteriolar dilatation was much more marked in the paralyzed upper than in the paralyzed lower extremity.

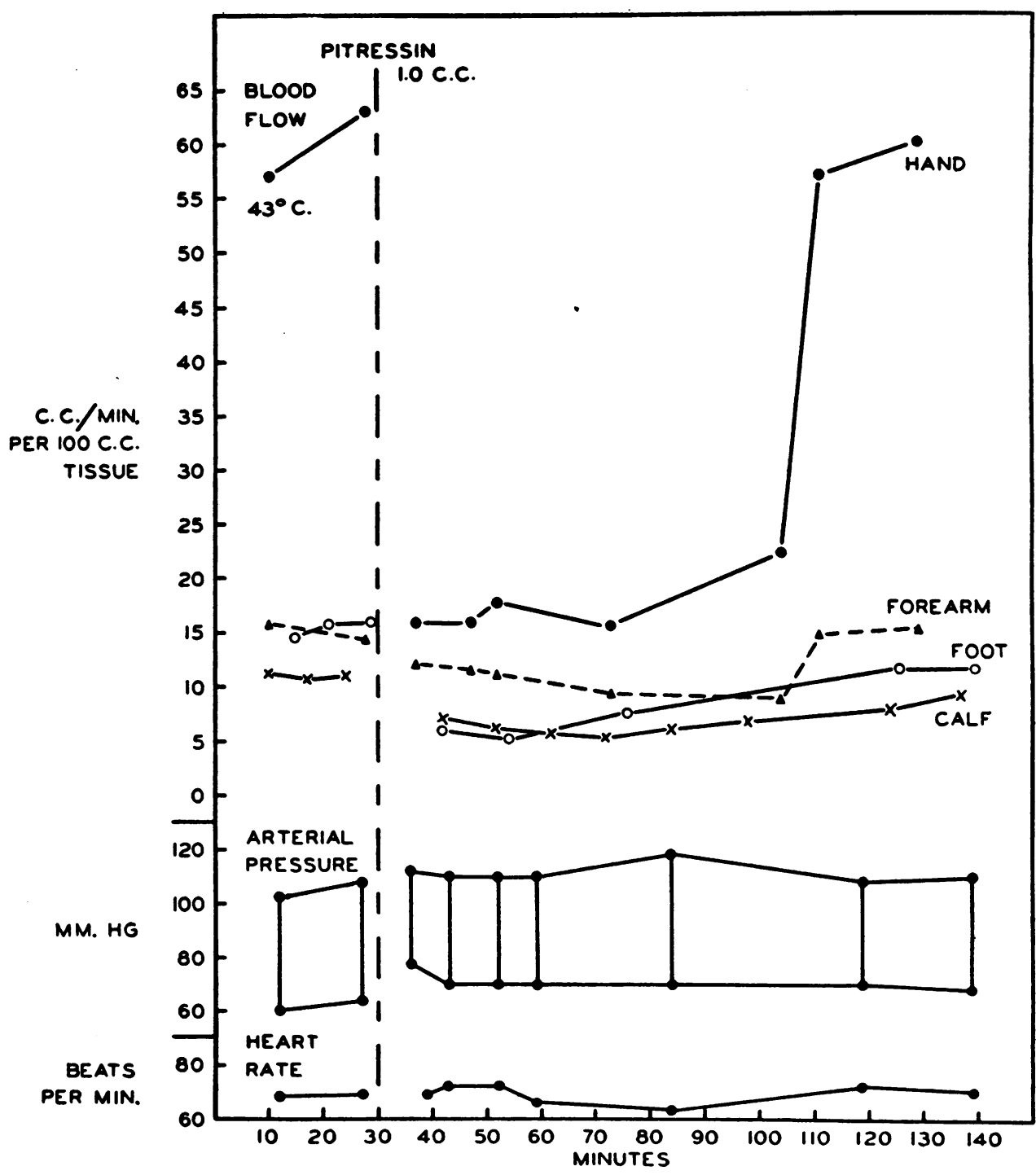

Fig. 6. Effect of Pitressin, 1 cc. Intramusculardy, on Blood Flow in the Hand, Forearm, Foot, and Calf at $43^{\circ} \mathrm{C}$.

Determinations on the hand and forearm were made simultaneously; the calf and foot measurements were from another subject. 
The observations reported show clearly that the peripheral blood flow in the extremities varies with the function of the tissue and that a stimulus that is very effective in increasing the blood flow in one tissue may cause relatively little response in another. The blood flow in the skin, particularly in the skin of the hands and feet, is regulated to a great degree by the need of the body to dissipate heat, and by heating the body the blood flow can be increased many times above that required for metabolism of the tissues. The blood flow in the muscles, however, is not directly concerned with heat dissipation and is not greatly increased even by local heat. Thus, heating the body or a part of the body appears primarily to drive the blood to the skin, especially to that of the hands and the feet. In contrast, exercise is a very effective stimulus for increasing the blood flow in the muscles, and the ability of the vessels of the muscles to dilate in response to exercise is little influenced by external heat ranging from 32 to $43^{\circ} \mathrm{C}$.

The striking fall in blood flow in the hand and the foot after the subcutaneous administration of $1 \mathrm{cc}$. of epinephrine is in marked contrast to the moderate rise in flow in the forearm and the calf. Since the vasomotor responses of the skin of the forearm and the calf seem to be in the same direction as the responses of the hand and the foot, it is logical to assume that the epinephrine causes some degree of constriction in the vessels of the skin of the forearm and the calf. If this is true, relatively more blood flows through the muscles than is indicated by the increase in total forearm flow. From these experiments it is impossible to say that the vessels of the muscles actually dilated as a result of the local action of the drug. The observed increases in flow might have been the result of the increased cardiac output forcing blood through vessels whose caliber had not changed. However, Grant and Pearson (5) state that epinephrine given intravenously in amounts small enough to cause only a transient rise in pulse rate and but a slight fall in systolic pressure produces vasodilatation in the forearm and the calf with an increase in the blood flow. Moreover, Weiss (13) has shown that the cardiac output remains elevated even after the pulse rate and the blood pressure have returned to normal, indicating that the blood flow in at least some portions of the body must still be elevated. This vasodilatation may be the result of the increased production of lactic acid from muscle glycogen and of the increased basal metabolism induced by epinephrine, rather than a direct action of the drug on the vessels themselves. It has been shown that, in man, after the intravenous injection of small amounts of epinephrine the pulse rate and blood pressure return to normal much sooner than the blood lactic acid (14). A difference in the response of the vessels of the skin and muscles to body heating and to epinephrine has also been demonstrated by measurements of the local temperature. It has been shown by the use of thermocouples (15) that the application of heat to the upper extremities produces striking elevation in the surface temperature of the feet but has no effect on the temperature of the leg muscles, and that following spinal anesthesia the temperature of the muscles remains unchanged while the temperature of the surface of the skin becomes elevated. Following the injection of epinephrine a pronounced rise in muscle temperature with a striking fall in surface skin temperature was observed.

The effects of epinephrine, 1 cc. of $1 / 1000$ solution subcutaneously, and of pitressin, $1 \mathrm{cc}$. intramuscularly, on the flow in the dilated hand and foot are quite similar; both cause a decrease in flow of about equal degree. Their effects on the circulation as a whole and on the blood flow in the muscles are quite different. Epinephrine causes a well marked increase in pulse rate, systolic pressure, pulse pressure, and minute output of the heart (16); the diastolic pressure is lowered. Pitressin, on the other hand, causes little change in pulse rate or blood pressure and no change in minute output (16). These differences are shown in the study of the peripheral blood flow in the forearm and the calf at $43^{\circ} \mathrm{C}$.; after epinephrine the flow increases and after pitressin it decreases. The vessels of the skin of the hand and the foot being equally sensitive to epinephrine and pitressin, it may be argued that the vessels of the skin of the forearm and the calf respond in the same way as those of the hand and the foot, though to a lesser degree; the decrease in the flow in the forearm and the calf at $43^{\circ} \mathrm{C}$. after pitressin being due to vasoconstriction in the skin and part of the increase in muscle flow after epine- 
phrine being masked by a similar decrease in skin flow.

\section{SUMMARY AND CONCLUSIONS}

1. Following strong sensory stimuli, such as pinching the skin until pain is caused, or a sudden, loud noise, the forearm and calf respond in three ways: (1) by a decrease in volume after a latent period of from 3 to 9 seconds; (2) by an increase in volume after a latent period usually not exceeding 2 seconds; (3) by a biphasic response with first an increase in volume with a short latent period usually not exceeding 2 seconds, and subsequently a decrease in volume.

2. Reasons are stated for the belief that the decrease in volume is the result of active reflex vasoconstriction, while the increase in volume is the result of a transient increase in cardiac output and a passive distension of the vascular bed.

3. The sensitivity of vasomotor responses varies considerably in different persons. Variations in the same individual have been observed from time to time.

4. The vessels of the upper part of the body are more sensitive to physical, chemical, and nervous stimuli than those of the lower part of the body.

5. The blood flow induced by local heat of $43^{\circ}$ C. is greater in the hand and foot than in the forearm and calf even when the mass of muscle present in the forearm and calf is disregarded and when the blood flow is recorded as cubic centimeters per minute per $100 \mathrm{sq} . \mathrm{cm}$. of surface area.

6. Local heat of $43^{\circ} \mathrm{C}$. produces nearly complete vasodilatation in the skin, but only relatively slight vasodilatation in the underlying muscles.

7. Exercise is a very effective stimulus for producing vasodilatation in the muscles, but not in the skin. The ability of the muscle vessels to dilate in response to exercise is not appreciably influenced by varying the external temperature between 32 and $43^{\circ} \mathrm{C}$.

8. Epinephrine, 1 cc. of $1 / 1000$ solution subcutaneously, causes a marked decrease in blood flow in the hand and the foot and a moderate increase in the blood flow in the forearm and the calf, both at 32 and at $43^{\circ} \mathrm{C}$.

9. Pitressin, 1 cc. intramuscularly, causes as great a decrease in blood flow in the hand and the foot at $43^{\circ} \mathrm{C}$. as does epinephrine. At $43^{\circ} \mathrm{C}$. it causes a moderate decrease in flow in the forearm and calf.

10. Neither epinephrine nor pitressin interferes with the dilatation of the muscle vessels in response to exercise or arterial occlusion.

11. The observation of Grant and Pearson (5) that unless the circulation to the hand is completely obstructed the plethysmographic method of measuring blood flow to the forearm is not accurate under all conditions has been confirmed.

This investigation was carried out with the technical assistance of Miss Sophia M. Simmons.

\section{BIBLIOGRAPHY}

1. Grant, R. T., and Bland, E. F., Observations on arteriovenous anastomoses in human skin and in the bird's foot with special reference to the reaction to cold. Heart, 1929-31, 15, 385.

2. Freeman, N. E., The effect of temperature on the rate of blood flow in the normal and in the sympathectomized hand. Am. J. Physiol., 1935, 113, 384.

3. Stead, E. A., Jr., and Kunkel, P., A plethysmographic method for the quantitative measurement of the blood flow in the foot. J. Clin. Invest., 1938, 17, 711.

4. Lewis, T., and Grant, R., Observations upon reactive hyperaemia in man. Heart, 1925, 12, 73.

5. Grant, R. T., and Pearson, R. S. B., The blood circulation in the human limb; observations on the differences between the proximal and distal parts and remarks on the regulation of body temperature. Clin. Sc., 1938, 3, 119.

6. Kunkel, P., and Stead, E. A., Jr., Blood flow and vasomotor reactions in the foot in health, in arteriosclerosis, and in thromboangiitis obliterans. J. Clin. Invest., 1938, 17, 715.

7. Gasser, H. S., and Meek, W. J., A study of the mechanisms by which muscular exercise produces acceleration of the heart. Am. J. Physiol., 1914, 34, 48.

8. Bainbridge, F. A., On some cardiac reflexes. J. Physiol., 1914, 48, 332.

9. Grant, R. T., and Holling, H. E., Further observations on the vascular responses of the human limb to body warming; evidence for sympathetic vasodilator nerves in the normal subject. Clin. Sc., 1938, 3, 273.

10. Weiss, S., Robb, G. P., and Ellis, L. B., The systemic effects of histamine in man, with special reference to the responses of the cardiovascular system. Arch. Int. Med., 1932, 49, 360.

11. Ellis, L. B., and Weiss, S., A study of the cardiovascular responses in man to the intravenous and intra-arterial injection of acetylcholine. J. Pharmacol. and Exper. Therap., 1932, 44, 235. 
12. Ellis, L. B., and Weiss, S., Vasomotor disturbance and edema associated with cerebral hemiplegia. Arch. Neurol. and Psychiat., 1936, 36, 362.

13. Weiss, S., Unpublished observations.

14. Cori, C. F., and Buchwald, K. W., Effect of continuous intravenous injection of epinephrine on the carbohydrate metabolism, basal metabolism and vascular system of normal men. Am. J. Physiol., 1930, 95, 71.

15. Friedlander, M., Silbert, S., Bierman, W., and
Laskey, N., Differences in temperature of skin and muscles of the lower extremities following various procedures. Proc. Soc. Exper. Biol. and Med., 1938, 38, 150.

16. Starr, I., Gamble, C. J., Margolies, A., Donal, J. S., Jr., Joseph, N., and Eagle, E., A clinical study of the action of 10 commonly used drugs on cardiac output, work and size; on respiration, on metabolic rate and on the electrocardiogram. J. Clin. Invest., 1937, 16, 799. 